\title{
Triazophos induced neuro-splenic toxicity and evaluation of antioxidative potential of aqueous Broccoli extract in Wistar albino rats
}

\author{
Dharmender Sharma* \\ Department of Zoology, Akal University, Talwandi Sabo -151302 (Punjab), India \\ Gurinder Kaur Sangha \\ Department of Zoology, Punjab Agricultural University, Ludhiana-141004 (Punjab), India \\ *Corresponding author. Email: dsk686@gmail.com
}

Article Info

https://doi.org/10.31018/

jans.v13i2.2644

Received: April 5, 2021

Revised: May 27, 2021

Accepted: May 30, 2021

\section{How to Cite}

Sharma, D. and Sangha, G. K.. (2021). Triazophos induced neuro-splenic toxicity and evaluation of antioxidative potential of aqueous Broccoli extract in Wistar albino rats. Journal of Applied and Natural Science, 13(2), 616 - 626. https:// doi.org/10.31018/jans.v13i2.2644

\begin{abstract}
The present investigation was carried out to assess the antioxidative potential of Broccoli sprouts aqueous extract (BE) against triazophos (TZ) induced oxidative stress (OS) in brain and spleen. In the experimental setup, six groups of rats were formed; Control (group 1), BE (group 2), TZ (group 3), and also BE+TZ groups such as BE1 (group 4), BE2 (group 5) and BE3 (group 6) groups. Rats were orally intubated for 30 days as per experimental design. After sacrifice, OS biomarkers viz; catalase (CAT), superoxide dismutase (SOD), glutathione reductase (GR), glutathione peroxidase (GPx), glutathione-S-transferase (GST), and lipid peroxidation (LPO) levels were determined in brain and spleen. Acetylcholinesterase (AChE) activity was observed in plasma and brain samples. Histological study of the spleen in TZ rats showed increased thickness of capsule, congestion and hypocellularity in follicles of spleen's white pulp and the histoarchitecture was restored in TZ+BE group rats. TZ caused degenerative changes in brain histology and rats showed mild congestion along with haemorrhage in the cerebral cortex. Results suggest that TZ exposure is associated with neural toxicity along with altered spleen stress biomarkers, which further corroborates with histopathological findings. It is inferred that BE exerts multi-mechanistic protective effects against TZ induced neuro-splenic toxicity which is attributable to its protective antioxidant actions.
\end{abstract}

Keywords: Antioxidant enzymes, Brain, Broccoli Extract, Spleen, Triazophos

\section{INTRODUCTION}

Environmental contamination associated with irrational use of pesticides is a serious issue for global public health, as these are used for managed agricultural and other domestic practices worldwide. Excessive pesticides use not only affects target species but also has potential to affect the health of non-target species, through the generation of reactive oxygen species (ROS) which ultimately cause a condition of oxidative stress (OS) (Agrawal and Sharma, 2010; Ghosh and Philip, 2006). Organophosphorus (OP) pesticides account for more than half of the total world pesticides consumptions as they are cost-effective and used against a wide range of pests, thus their exposure is a major public health issue ( $\mathrm{Li}$ et al., 2008). Triazophos, an $\mathrm{OP}$, is being extensively used in agricultural and aquaculture activities throughout the globe, but it has a potential risk to human health as well as to ecological system due to its chemical stability and low degradation rate (Sharma et al., 2015; Wu et al., 2017). OPs are primarily recognized for their neurotoxic effects in mammals and higher vertebrates through the inhibition of acetylcholinesterase (AChE), which leads to the accumulation of neurotransmitter acetylcholine and have been found toxic to axonal transport of neurons along with neuroinflammation and cognitive impairment (Chen et al., 2017; Gao et al., 2017). OPs induced OS, is also assessed by number of stress biomarkers such as differential levels of malondialdehyde (MDA), i.e. end product of lipid peroxidation (LPO) and by modified endogenous antioxidants activity levels like catalase (CAT), superoxide dismutase (SOD), glutathione-Stransferase (GST) and glutathione peroxidase (GPX). Altered stress biomarkers can lead to the development of moderate to severe pathophysiological changes (Sharma and Sangha, 2014; Sharma et al., 2014).

Fruits, vegetables, and herbal extracts rich in antioxi- 
dants have been used traditionally to strengthen the natural immune system without fear of its negative effects on the body and slow down the oxidative damage caused by ROS (Cekic et al., 2011; Katiyar et al., 2012). These days much attention has been paid to the protective effects of natural antioxidants that fight chemical toxins and associated pathophysiological conditions (Gao et al., 2003; Vouldoukis et al., 2004). Studies with cruciferous vegetables rich in antioxidants such as broccoli, contain a large number of active antioxidants such as polyphenols, glucosinolates, vitamin C and flavonoids, suggest a protective potential that stimulates defense mechanisms through the elimination of ROS by inducing endogenous antioxidants (Jeffery and Araya, 2009; Koh et al., 2009).

The effects of toxins, associated with organs toxicity and stress, are known to cause major physiological or anatomical changes (Mansour and Mossa, 2010). The high lipid content in the brain makes it more vulnerable for free radicals mediated insult (Pajovic et al., 2003), while spleen plays an important role in establishing immunity (Wang et al., 2017). Number of studies have been made to evaluate the neuroprotective and immunity strengthening potential of natural antioxidants against different classes of pesticides and other environmental contaminants (Khan et al., 2017; Samida et al., 2017; Saoudi et al., 2017), but studies with laboratory animals regarding toxicokinetics and oxidative stress induction by TZ in brain and spleen are lacking. Therefore present investigation was carried out to study the ameliorative potential of aqueous extract of broccoli sprouts against the TZ induced toxicity in the brain and spleen of female Wistar rats.

\section{MATERIALS AND METHODS}

\section{Chemicals}

All chemicals were purchased from SRL Pvt. Ltd, Sigma-Aldrich, SD Fine-Chem Ltd, or were among the highest grades of analysis. Ashirwad Industries in Mohali provided standard rat feeds, while Triazophos as a Truzo 40 EC was purchased from Meghmani Organics Limited, Charodi, India.

\section{Plant sample preparation}

Seeds of Brassica oleracea var. italica, were procured (form Department of Vegetable Sciences, Punjab Agricultural University, Ludhiana), grown and sprouts were harvested gently on 5 days and were further processed to a dry powdered form of broccoli extract (BE) as per Sharma and Sangha, (2018) protocol. Quantification of glucosinolates (GSLs), from the powder, was done by Moller et al. (1985), vitamin C by Adom et al. (2002), total polyphenols by Ainsworth and Gillespie (2007), and total flavonoids by Chang et al. (2007) with slight modifications. Total glucosinolates (GSLs) content was estimated for $200 \mathrm{mg}$ of dried sample and GSLs were considered as a base concentration alongwith other antioxidants in the extract (Table 1). For experimentation, three different doses of 10,20 and $30 \mu$ mols with respect to GSLs were made from $200 \mathrm{mg}$ dried BE powder in distilled water for subsequent use in the present investigation.

\section{Experimental design}

Female albino rats ageing 9-12 weeks and weighing 140-170 grams were obtained from the Department of Livestock Production and Management, Guru Angad Dev Veterinary and Animal Sciences University, Ludhiana. Two rats were housed in each polypropylene cages using bedding of paddy husk in the laboratory, where the optimized humidity of $55 \pm 5 \%$, temperature around $25 \pm 2^{\circ} \mathrm{C}$ and a 12 to 12 hours light-dark cycle of photoperiod were maintained. Feed and water were provided to housed animals during experimentation and guidelines of CPCSEA, India were used for animal handling, while experiments were duly approved by the "Institutional Animal Ethics Committee (IAEC)", GADVASU, Ludhiana (date: 06.08.2012 and letter no. 3901-35).

After ten days acclimatization, female rats were segregated into six groups with eight rats in each group as Group I Control rats; Group II as BE rats received 10 $\mu \mathrm{mol}$ of BE; Group III as TZ rats; Group IV as BE1 rats received TZ alongwith $10 \mu \mathrm{mol}$ of $\mathrm{BE}$; Group $V$ as BE2 rats received $T Z$ and $20 \mu \mathrm{mol}$ of $B E$ and Group VI as $B E 3$ rats received $T Z$ and $30 \mu \mathrm{mol}$ of $B E$. TZ was given as $1 / 10^{\text {th }}$ of $L D_{50}$, i.e. $8.2 \mathrm{mg} / \mathrm{kg}$ b.w. in olive oil, while control and $\mathrm{BE}$ rats were provided with an equal volume of olive oil. Rats with BE supplementation and TZ treatment were collectively referred as $\mathrm{BE}+\mathrm{TZ}$ rats. During 30 days oral intubation experiment, body weights were also recorded weekly.

\section{Organs weight, body weight and blood plasma preparation}

After experimentation, female rats were mildly anesthetized using chloroform and their blood sample was collected from the heart directly in heparinized vials for further processing. After that, blood was centrifuged for 15 minutes at 2300 r.p.m. and the supernatant as plasma was used for biochemical analysis. After dissection, brain and spleen were excised immediately, cleared off the adhering tissue and weighed.

\section{Biochemical and histological studies}

Eight rats from each group were analyzed for biochemical studies of the spleen, while five rats from each group were evaluated for the brain. For organs homogenate, $0.3 \mathrm{gm}$ of spleen and $0.5 \mathrm{gm}$ of the brain was homogenized in $2 \mathrm{ml}$ and $3 \mathrm{ml}$ of $0.1 \mathrm{M}$ PBS ( $\mathrm{pH} \mathrm{7.4)}$ were used respectively, centrifuged and the superna- 
Sharma, D. and Sangha, G. K.. / J. Appl. \& Nat. Sci. 13(2), 616 - 626 (2021)

Table 1. Broccoli sprouts extract with glucosinolates and other components for dose formation.

\begin{tabular}{llllll}
\hline Components & Units/ $\mathbf{g}$ of dry BE powder & $\boldsymbol{\mu}$ mol & $\begin{array}{l}\mathbf{3 0} \boldsymbol{\mu} \text { mol of } \\
\text { GSLs }\end{array}$ & $\begin{array}{l}\mathbf{2 0} \boldsymbol{\mu} \mathbf{~ m o l ~ o f ~} \\
\text { GSLs }\end{array}$ & $\begin{array}{l}\mathbf{1 0} \boldsymbol{\mu} \mathbf{~ m o l ~ o f ~} \\
\mathbf{G S L s}\end{array}$ \\
\hline Vitamin C & $16.57 \pm 1.45 \mu \mathrm{mol}$ & 16.57 & 4.569 & 3.046 & 1.523 \\
Total polyphenols & $\begin{array}{l}23.82 \pm 2.33 \mathrm{mg} \\
\text { gallic acid equivalents }\end{array}$ & 0.14 & 0.039 & 0.026 & 0.013 \\
Total flavonoids & $\begin{array}{l}0.045 \pm 0.003 \mathrm{mg} \text { quercetin } \\
\text { equivalents }\end{array}$ & $1.51 \times 10^{-4}$ & $4.16 \times 10^{-5}$ & $2.78 \times 10^{-5}$ & $1.39 \times 10^{-5}$ \\
Total glucosinolates & $108.80 \pm 3.13 \mu \mathrm{mol}$ & 108.8 & 30 & 20 & 10 \\
\hline
\end{tabular}

Values expressed as Mean \pm SE $(n=8)$. (GSLs: glucosinolates)

tant was used for the biochemical observations. Total proteins were estimated by Lowry et al. (1951); CAT (catalase) by Aebi, (1983); SOD (Superoxide Dismutase) by Marklund and Marklund, (1974); GR (glutathione reductase) by Carlberg and Mannervik, (1985); GST (glutathione-S-transferase) by Habig et al., (1974); GPx (glutathione peroxidase) by Hafeman et al., (1984); LPO (Lipid peroxidation) by Stocks and Dormandy (1971) and acetylcholinesterase activity in brain and plasma was assayed by Voss and Sachsse, (1970) method.

After dissection, brain and spleen were placed in $0.1 \mathrm{M}$ phosphate-buffered solution $(\mathrm{pH} 7.4)$ for $10 \mathrm{~min}$. Tissues were then immersed in alcoholic Bouin's fixative for 24 hours and subsequently dehydrated in graded series of alcohols, cleared in benzene and were finally embedded in paraffin wax (melting point $58-60^{\circ} \mathrm{C}$ ). The $5 \mu \mathrm{m}$ thick sagittal sections for the brain and spleen were prepared using a microtome and stained with hematoxylin and eosin and slides were observed and photographed under OLYMPUS $\mathrm{CH} 20 \mathrm{i}$ microscope. Routine laboratory microtome was used to get the $5 \mu \mathrm{m}$ thick sections and further tissue sections were stained by routine procedures with hematoxylin and eosin, and slides were studied and analyzed under OLYMPUS $\mathrm{CH} 20 \mathrm{i}$ microscope for photographs. For histopathological changes, 30 sections from each spleen and $40 \mathrm{sec}-$ tions were observed each for various regions of the brain.

\section{Statistical analysis}

Results are expressed as the mean \pm standard error of mean (SEM) for $n=8$. Analysis of statistical data was performed using CPCS1 and one ANOVA method was performed to determine any value and the statistical value criterion was set to $P<0.05$.

\section{RESULTS}

Body weight changes were comparable in all the experimental group rats, but a reduced growth rate was observed in TZ and all $\mathrm{BE}+\mathrm{TZ}$ rats as compared to control at $\mathrm{P}<0.05$ (Table 2). Brain weight was comparable while spleen weight was slightly reduced in TZ group rats and restored in group $\mathrm{V}$ and $\mathrm{VI}$ rats compared to TZ rats (Table 2). Investigation of spleen revealed that total protein content was comparable, while significantly reduced levels of CAT, GST, GPx and GR were observed in TZ treated rats compared to control rats at $\mathrm{P}<0.05$ (Table 3). CAT and GR levels were restored significantly in BE3 group rats. GPx activity levels were also significantly improved in all $\mathrm{BE}+\mathrm{TZ}$ group rats compared to $T Z$ treated rats. SOD activity levels were comparable in all experimental group rats. The activity levels of GST were significantly (at $\mathrm{P}<0.05$ ) restored in BE2 and BE3 group rats. LPO levels were high in TZ treated rats and were reversed significantly in all rats of $\mathrm{BE}+\mathrm{TZ}$ groups as compared to $\mathrm{TZ}$ treated rats at $\mathrm{P}<0.05$ (Table 3). Significant inhibition of plasma and brain AChE activity in TZ treated rats was noticed, and supplementation of broccoli extract significantly (at $\mathrm{P}<0.05$ ) restored $\mathrm{AChE}$ levels in brain of $\mathrm{BE} 3$ group rats and was also improved in plasma of $\mathrm{BE}+\mathrm{TZ}$ group rats compared to $T Z$ group rats (Table 4). Total protein content of brain was comparable in all the experimental group rats (Table 4). Significantly elevated levels of CAT were observed in all TZ and BE+TZ treated rats, while SOD activity levels were reduced significantly in $T Z$ group rats, and were significantly restored in BE3 group rats. GPx activity levels were significantly reduced with TZ treatment and were improved statistically in all BE+TZ group rats. GR and GST activity levels were comparable in all experimental group rats $(P<0.05)$ (Table 4). Significantly high LPO levels were observed in the brain of $T Z$ treated rats and were significantly restored in all $\mathrm{BE}+\mathrm{TZ}$ group rats at $\mathrm{P}<0.05$ (Table 4).

Histological study of the spleen in control rats showed well marked vascular organization and cellular composition in the white and red pulp of the spleen. TZ toxicity induced many histopathological conditions such as the increased thickness of capsule, congestion and hypocellularity in follicles of spleen's white pulp (Fig. 1 and 2). TZ treatment induced mild to moderate distortions in germinal centers of the spleen and the histoarchitecture was restored in all $\mathrm{TZ}+\mathrm{BE}$ group rats (Fig. 1, Table 5). Peripheral regions of the spleen in TZ treated rats showed disturbed outer cortex with increased marginal sinus thickness/ vacuolation compared to control (Fig. 1), which was improved by BE treatment in a dose -dependent manner TZ+BE group rats (Table 5).

Brain histology showed TZ caused degenerative 
Sharma, D. and Sangha, G. K.. / J. Appl. \& Nat. Sci. 13(2), 616 - 626 (2021)

Table 2. Effect of Triazophos and broccoli extract treatment on body weight (b.w.) and organ weight (g/100 g of b.w.) of treated female Wistar rats.

\begin{tabular}{lllllll}
\hline & Control & BE & TZ & BE1 & BE2 & BE3 \\
\hline Initial b.w. (g) & $161.75 \pm 4.19$ & $162.50 \pm 5.76$ & $163.52 \pm 4.57$ & $160.75 \pm 4.84$ & $164.50 \pm 3.87$ & $164.75 \pm 5.03$ \\
Final b.w. (g) & $195.50 \pm 4.145$ & $196.75 \pm 5.31$ & $190.45 \pm 3.43$ & $187.72 \pm 3.67$ & $195.75 \pm 3.21$ & $193.50 \pm 4.11$ \\
Growth rate (g/ & $0.43 \pm .09$ & $0.44 \pm 0.02$ & $0.34 \pm 0.06$ & $0.35 \pm 0.04$ & $0.37 \pm 0.03$ & $0.35 \pm 0.06$ \\
day/100g b.w./rat) & $0.239 \pm 0.011$ & $0.246 \pm 0.005$ & $0.224 \pm 0.011$ & $0.233 \pm 0.013$ & $0.241 \pm 0.002$ & $0.243 \pm 0.009$ \\
Spleen & $0.952 \pm 0.019$ & $0.957 \pm 0.023$ & $0.946 \pm 0.012$ & $0.951 \pm 0.021$ & $0.955 \pm 0.026$ & $0.957 \pm 0.029$ \\
Brain &
\end{tabular}

Values expressed as Mean \pm SE $(n=8)$; *Significant difference $(P \leq 0.05)$ as compared to control;^Significant difference $(P \leq 0.05)$ as compared to TZ ; BE : Broccoli extract; TZ: Triazophos; BE1: $10 \mu \mathrm{mol}$ of broccoli extract and Triazophos; BE2: $20 \mu \mathrm{mol}$ of broccoli extract and Triazophos; BE3: $30 \mu \mathrm{mol}$ of broccoli extract and Triazophos.

Table 3. Effect of TZ and broccoli extract treatment on spleen biochemical stress markers.

\begin{tabular}{lllllll}
\hline Parameter & Control & BE & TZ & BE1 & BE2 & BE3 \\
\hline Protein & $6.35 \pm 0.45$ & $6.67 \pm 0.43$ & $5.87 \pm 0.56$ & $7.02 \pm 0.67$ & $6.85 \pm 0.41$ & $6.70 \pm 0.47$ \\
CAT & $9.89 \pm 0.17$ & $10.59 \pm 0.13$ & $4.09 \pm 0.09^{*}$ & $5.67 \pm 0.09^{\star}$ & $5.81 \pm 0.12^{*}$ & $7.66 \pm 0.09^{\star \wedge}$ \\
SOD & $18.55 \pm 0.54$ & $19.32 \pm 0.52$ & $20.79 \pm 0.63$ & $19.78 \pm 0.57$ & $19.05 \pm 0.69$ & $19.28 \pm 0.46$ \\
GST & $0.076 \pm 0.004$ & $0.081 \pm 0.005$ & $0.030 \pm 0.003^{*}$ & $0.035 \pm 0.003^{\star}$ & $0.053 \pm 0.005^{\star \wedge}$ & $0.068 \pm 0.008^{\wedge}$ \\
GPx & $0.52 \pm 0.01$ & $0.45 \pm 0.05$ & $0.23 \pm 0.04^{*}$ & $0.35 \pm 0.02^{\star \wedge}$ & $0.48 \pm 0.08^{\wedge}$ & $0.57 \pm 0.08^{\wedge}$ \\
GR & $0.075 \pm 0.004$ & $0.077 \pm 0.004$ & $0.049 \pm 0.005^{\star}$ & $0.053 \pm 0.005^{\star}$ & $0.059 \pm 0.006^{\star}$ & $0.077 \pm 0.006^{\wedge}$ \\
LPO & $4.08 \pm 0.01$ & $4.03 \pm 0.05$ & $6.65 \pm 0.02^{*}$ & $4.39 \pm 0.04^{\wedge}$ & $4.32 \pm 0.03^{\wedge}$ & $4.24 \pm 0.06^{\wedge}$ \\
\hline
\end{tabular}

Units: Proteins (mg/100 mg tissue), CAT ( $\mu$ mole of $\mathrm{H}_{2} \mathrm{O}_{2}$ decomposed/min/mg protein), SOD (U/mg protein), GST ( $\mu$ moles of GSHCDNB conjugate formed/ min/mg protein), GR ( $\mu$ moles of NADPH oxidized/ min/mg protein), GPx (U/mg protein), LPO (nM MDA/100 $\mathrm{mg}$ tissue); Values expressed as Mean $\pm \mathrm{SE}(n=8)$; ${ }^{*}$ Significant difference $(P \leq 0.05)$ as compared to control; ^ Significant difference $(P \leq$ 0.05) as compared to TZ ;BE : Broccoli extract; TZ: Triazophos; BE1: $10 \mu \mathrm{mol}$ of broccoli extract and Triazophos; BE2: $20 \mu \mathrm{mol}$ of broccoli extract and Triazophos; BE3: $30 \mu \mathrm{mol}$ of broccoli extract and Triazophos.

changes in the brain of rats (Fig. 3-6). TZ treated rats showed mild congestion and haemorrhage in internal regions of the cerebral cortex, and all TZ+BE treated group rats showed improvement with broccoli extract supplementation (Fig. 3,4). Congestion and haemorrhage were characterized by the number of microglial cells found in association with normal looking neurons in CNS due to TZ induced neural toxicity (Fig. 3, Table 6). The cerebral cortex of TZ treated rats showed a number of degenerating neurons, pyknotic neurons, shrunken neurons and neuron swelling along with vacuolation, which were reduced in all BE+TZ treated rats (Fig. 4, Table 6). In the hippocampus region of brain the unique monomorphic pattern of neurons within its pyramidal layer was slightly compressed in TZ treated rats as compared to control and TZ+BE group rats (Fig. 5 ), while subcommissural organ, which is helpful in clearance of certain compounds from the circulation of the cerebrospinal fluid, was observed with distorted ependymal cells in TZ treated rats (Fig. 6, Table 6).

\section{DISCUSSION}

Organophosphorus pesticides are most widely used insecticides and have been implicated in numerous toxicity based public health problems (Leibson and Lifshutz 2008; Sharma et al., 2015a). Further ameliorative studies have shown that increased consumption of antioxidant-rich vegetables as broccoli, can reduce the risk of stress and disease conditions (Chen et al., 2008; Sajeesh et al., 2011). Decreased growth rate with TZ treatment, which was further improved with BE supplementation, is in accordance with many studies (Uzun and Kalender 2011; Sharma and Sangha 2014), which suggest that OP intoxication can cause decreased body weight and growth rate in animals. Broccoli extract has the ameliorative potential to restore the normal growth rates and organs weight, which is supported by a number of studies where broccoli sprouts were found beneficial in rats (Sharma and Sangha 2018; Paśko et al., 2018).

Spleen is a more sensitive organ of the body to pesticides exposures and exposure of OPs are more hazardous at the environmentally-relevant low dose, as OPs act as the inhibitor of the cellular immune response in the spleen and can lead to a number of unknown immune system associated disorders (Wang et al., 2017). Also, the spleen is the site of direct and indirect toxicity and a target for some carcinogens (Babaei et al., 2015). Endogenous antioxidants are involved in 
Sharma, D. and Sangha, G. K.. / J. Appl. \& Nat. Sci. 13(2), 616 - 626 (2021)

Table 4. Effect of TZ and Broccoli extract treatment on brain biochemical stress.

\begin{tabular}{|c|c|c|c|c|c|c|}
\hline Parameter & Control & BE & TZ & BE1 & BE2 & BE3 \\
\hline Protein & $8.18 \pm 0.56$ & $8.22 \pm 0.67$ & $7.41 \pm 0.43$ & $8.01 \pm 0.31$ & $7.78 \pm 0.67$ & $7.80 \pm 0.56$ \\
\hline CAT & $15.15 \pm 0.36$ & $15.87 \pm 0.34$ & $19.68 \pm 0.86^{*}$ & $21.87 \pm 1.04^{*}$ & $21.74 \pm 1.87^{*}$ & $21.66 \pm 1.17^{*}$ \\
\hline SOD & $5.21 \pm 0.09$ & $5.29 \pm 0.09$ & $2.31 \pm 0.22^{*}$ & $2.44 \pm 0.20^{*}$ & $2.87 \pm 0.16^{*}$ & $3.64 \pm 0.14^{* \wedge}$ \\
\hline GST & $0.036 \pm 0.001$ & $0.037 \pm 0.001$ & $0.036 \pm 0.002$ & $0.039 \pm 0.002$ & $0.039 \pm 0.002$ & $0.042 \pm 0.002$ \\
\hline GPx & $0.52 \pm 0.01$ & $0.50 \pm 0.03$ & $0.23 \pm 0.03^{*}$ & $0.37 \pm 0.03^{* \wedge}$ & $0.48 \pm 0.03^{\wedge}$ & $0.67 \pm 0.04^{* \wedge}$ \\
\hline GR & $0.006 \pm 0.001$ & $0.006 \pm 0.000$ & $0.007 \pm 0.001$ & $0.008 \pm 0.001$ & $0.008 \pm 0.001$ & $0.008 \pm 0.001$ \\
\hline LPO & $3.02 \pm 0.06$ & $2.98 \pm 0.04$ & $4.84 \pm 0.04^{*}$ & $3.63 \pm 0.05^{\star \wedge}$ & $3.43 \pm 0.04^{* \wedge}$ & $3.22 \pm 0.03^{\wedge}$ \\
\hline $\begin{array}{l}\text { Brain AChE } \\
(\mathrm{U} / \mathrm{t})\end{array}$ & $865.54 \pm 7.27$ & $860.95 \pm 6.63$ & $690.45 \pm 6.67^{*}$ & $714.45 \pm 6.68^{*}$ & $735.67 \pm 5.23^{*}$ & $744.43 \pm 5.43^{* \wedge}$ \\
\hline $\begin{array}{l}\text { Plasma } \\
\text { AChE (U/lt) }\end{array}$ & $842.54 \pm 4.67$ & $850.75 \pm 6.23$ & $603.45 \pm 7.67^{*}$ & $654.45 \pm 7.78^{* \wedge}$ & $692.43 \pm 5.23^{* \wedge}$ & $699.67 \pm 7.43^{* \wedge}$ \\
\hline
\end{tabular}

Units: Proteins (mg/100 mg tissue), CAT ( $\mu$ mole of $\mathrm{H}_{2} \mathrm{O}_{2}$ decomposed/min/mg protein), SOD (U/mg protein), GST ( $\mu$ moles of GSHCDNB conjugate formed/ min/mg protein), GR ( $\mu$ moles of NADPH oxidized/ min/mg protein), GPx (U/mg protein), LPO (nM MDA/100 $m g$ tissue); Values expressed as Mean \pm SE ( $n=8$ for plasma and $n=5$ for brain); ${ }^{*}$ Significant difference $(P \leq 0.05)$ as compared to control $\wedge$ Significant difference $(\mathrm{P} \leq 0.05)$ as compared to TZ ; BE : Broccoli extract; TZ: Triazophos; BE1: 10 mol of broccoli extract and Triazophos; BE2: $20 \mu \mathrm{mol}$ of broccoli extract and Triazophos; BE3: $30 \mu \mathrm{mol}$ of broccoli extract and Triazophos.

Table 5. Histopathological changes in spleen after treatment with TZ and aqueous extract of broccoli sprouts in female Wistar rats.

\begin{tabular}{|c|c|c|c|c|c|c|c|}
\hline S. No. & Feature & Control & BE & TZ & BE1 & BE2 & BE3 \\
\hline 1 & $\begin{array}{l}\text { Red pulp } \\
\text { abnormality }\end{array}$ & - & - & - & - & - & - \\
\hline 2 & $\begin{array}{l}\text { Degenerated } \\
\text { Germinal centers }\end{array}$ & - & - & +++ & ++ & ++ & ++ \\
\hline 3 & Distorted PALS & - & - & ++ & ++ & + & + \\
\hline 4 & Necrosis & - & - & + & + & + & + \\
\hline 5 & $\begin{array}{l}\text { Thickness of } \\
\text { capsule }\end{array}$ & $\mathrm{N}$ & $\mathrm{N}$ & $\uparrow$ ed, +++ & $\uparrow e d,++$ & $\uparrow$ ed, ++ & + \\
\hline 6 & $\begin{array}{l}\text { Marginal Sinus } \\
\text { thickness }\end{array}$ & - & - & ++ & ++ & + & + \\
\hline
\end{tabular}

- nil; + minimal (<10\%); ++ mild (<25\%); +++ moderate (<40\%); N: normal; $\uparrow$ ed: increased; BE : Broccoli extract; TZ: Triazophos; BE1: $10 \mu \mathrm{mol}$ of broccoli extract and Triazophos; BE2: $20 \mu \mathrm{mol}$ of broccoli extract and Triazophos; BE3: 30 $\mu \mathrm{mol}$ of broccoli extract and Triazophos.

maintaining the healthy state of the body against free radicals mediated tissue or cellular damage (Chaudiere and Ferrari-iliou 1999). CAT, GST, GPx and GR activity levels were significantly reduced in the spleen of $T Z$ treated rats, and were restored in all $B E+T Z$ group rats. SOD, CAT, GPx, GST and other endogenous antioxidants play an important role in maintaining the redox potential of the cell by regulating the production and clearance of free radicals (Hu et al., 2014).

Broccoli extract coordinates various phase II detoxification enzyme systems, thereby having protective effects on oxidative stress (Guerrero-Beltrán et al., 2012) and has protective efficacy against pesticide induced toxicity. Major cytoprotective effects of sulforaphane, a type of GSL, are driven by the increased expression of Kelch-like ECH-associated protein 1 (Keap1), Nuclear factor erythroid 2 (Nrf2) pathway, anti-inflammatory mechanisms including inhibition of the NF-KB pathway etc (Baird and Dinkova-Kostova 2011; Gerhauser 2013). Nrf2 play a critical role in protecting and maintaining spleen (Zhan et al., 2017) and brain (Ren et al., 2011) health from toxic chemicals and other stressinducing factors. Elevated LPO levels, in terms of MDA, in TZ-treated rats was reversed in all BE+TZ group rats, suggest that $B E$ can reduce lipid peroxidation by increasing the activity of the antioxidant enzyme and improving the free radical clearance ability of the spleen. These observations are in agreement with a number of studies on rats (Mohamadin et al., 2010; Singh et al., 2013; Hu et al., 2014) where natural antioxidants have resulted in reduced MDA levels with restored organ homeostasis, thus consolidates present 
Sharma, D. and Sangha, G. K.. / J. Appl. \& Nat. Sci. 13(2), 616 - 626 (2021)

Table 6. Histopathological changes in brain of TZ and broccoli extract treated Wistar rats.

\begin{tabular}{llllllll}
\hline S. No. & Feature & Control & BE & TZ & BE1 & BE2 & BE3 \\
\hline 1 & Congestion & - & - & + & + & + & + \\
2 & Pyknosis/ Necrosis & + & + & +++ & ++ & ++ & ++ \\
3 & Neuronal vacuolation & - & - & +++ & ++ & + & + \\
4 & Neuronal degeneration & - & - & ++ & + & + & + \\
5 & Edema & - & - & - & - & - \\
6 & Haemorrhage & - & - & + & - & - & - \\
\hline
\end{tabular}

- nil; + minimal $(<10 \%) ;++$ mild $(<25 \%) ;+++$ moderate $(<40 \%)$; BE : Broccoli extract; TZ: Triazophos; BE1: $10 \mu$ mol of broccoli extract and Triazophos; BE2: $20 \mu \mathrm{mol}$ of broccoli extract and Triazophos; BE3: $30 \mu \mathrm{mol}$ of broccoli extract and Triazophos.
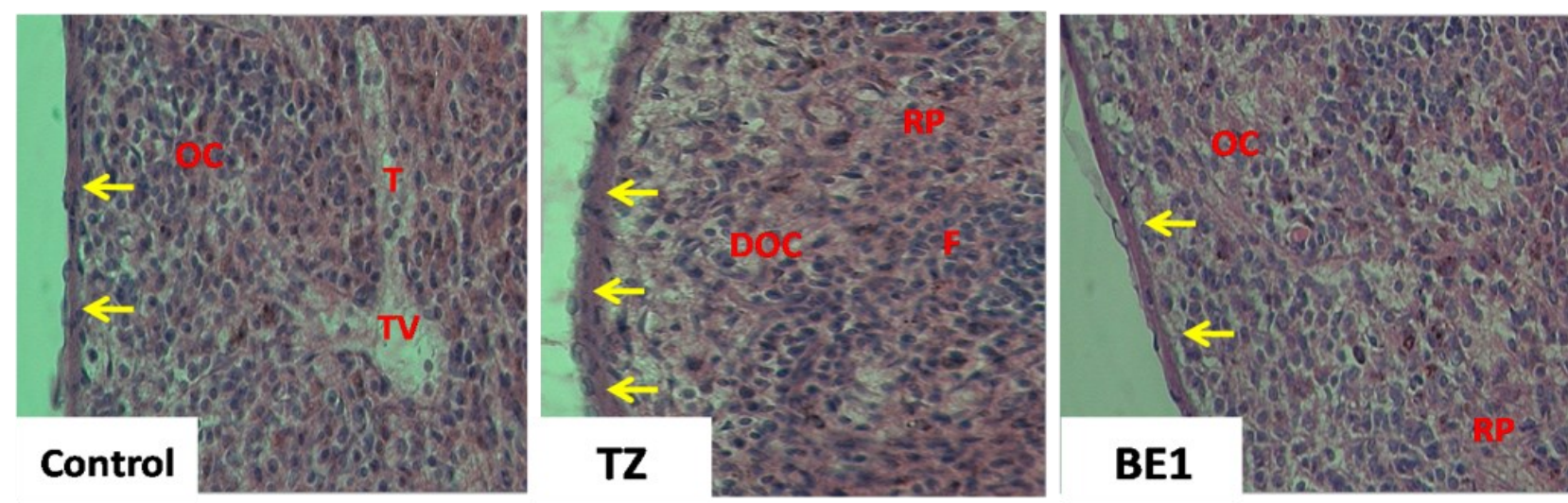

Fig. 1. Effect of broccoli extract on spleen histology against TZ induced toxicity (Magnification: 400x, Stain: Eosin and hematoxylin; Control: Control group rats; TZ: Triazophos; BE1: $10 \mu \mathrm{mol}$ of broccoli extract and Triazophos). F: follicle; T: trabeculus; TV: trabecular vein; OC: outer cortex; DOC: disturbed outer cortex; RP: red pulp; Yellow arrow showing the variation in thickness of capsule.
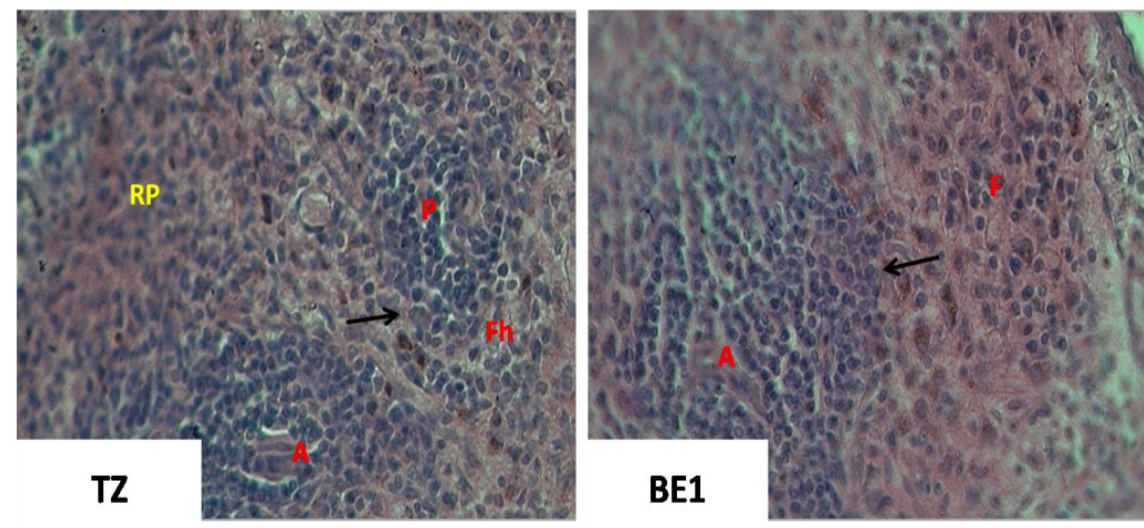

Fig. 2. Effect of broccoli extract on spleen histoarchitecture against TZ induced toxicity (Magnification: 400x, Stain: Eosin and hematoxylin). F: follicles; Fh: follicles showing hypocellularity; P: PALS sparsely populated by T-cells in TZ rats; marginal zone disturbed in TZ rats (black arrow).

findings.

Xenobiotics metabolism and xenobiotic-related signaling pathways are key factors in activating xenobiotic toxicity (Wu et al., 2017a). The neuroprotective role of glucosinolate in the brain has been evidenced in the upregulation of defense mechanisms (Giacoppo et al., 2014). $B E$ restored $A C h E$ levels in all $B E+T Z$ group rats and similar observations have been observed for AChE in the brain of rats treated with chlorpyrifos and grape seed extract rich in natural antioxidants (Singh et al., 2013), in trichlorfon plus hydroxycinnamic acid treated rats (Sharma and Singh 2012), revealing the protective effect of broccoli extract. CAT activity level was significantly increased and SOD activity was reduced with $T Z$ treatment, while $B E+T Z$ group rats restored these levels compared to $\mathrm{TZ}$ group rats. SOD has been reported with same activity behaviour in brain tissue of rats treated with propoxur, a widely used carbamate insecticide, 

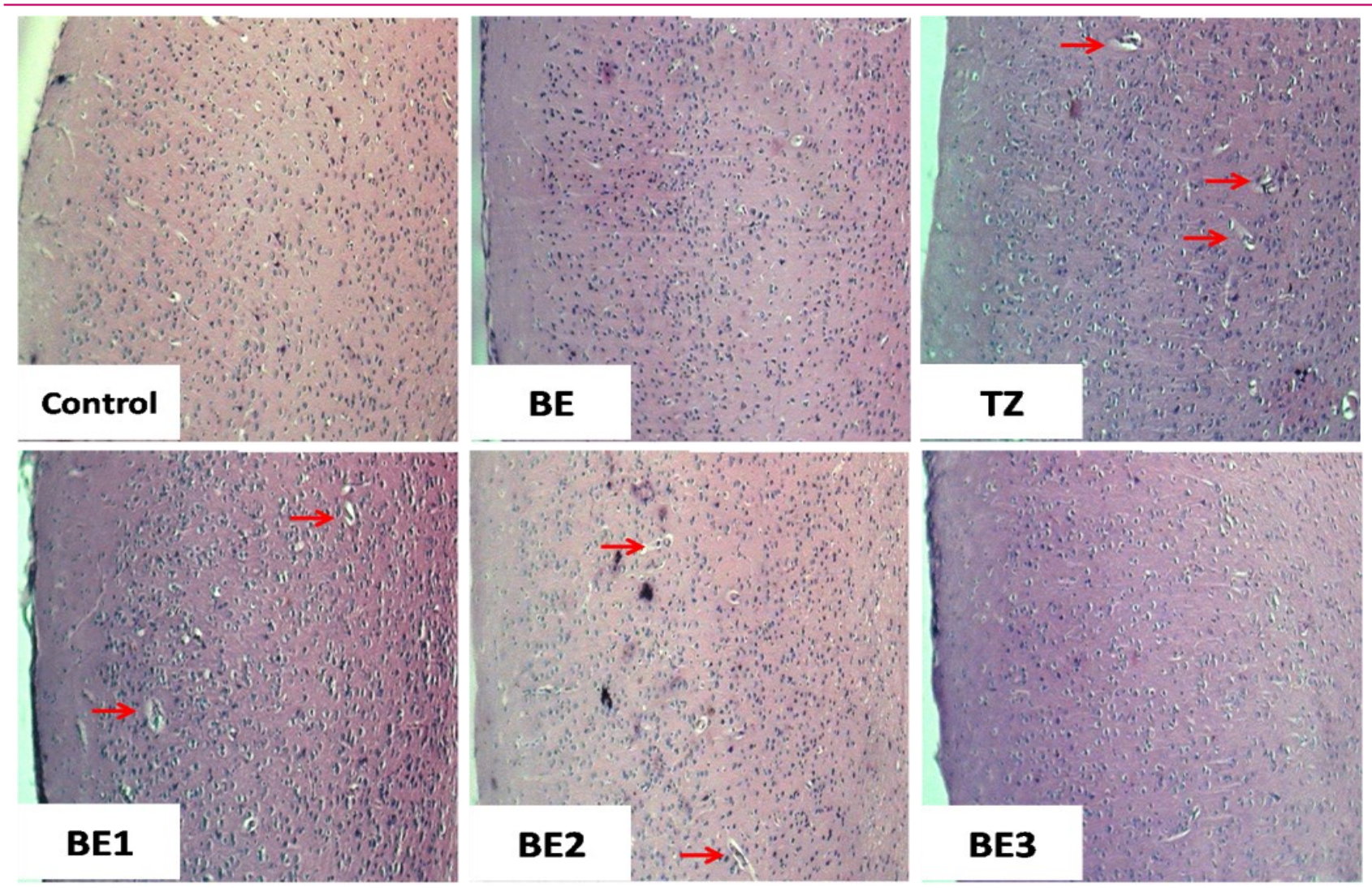

Fig. 3. Effect of broccoli extract on cerebral histoarchitecture against TZ induced toxicity (Magnification: 100x, Stain: Eosin and hematoxylin) Arrows showing microglial cells found in association with normal looking neurons due to TZ toxicity
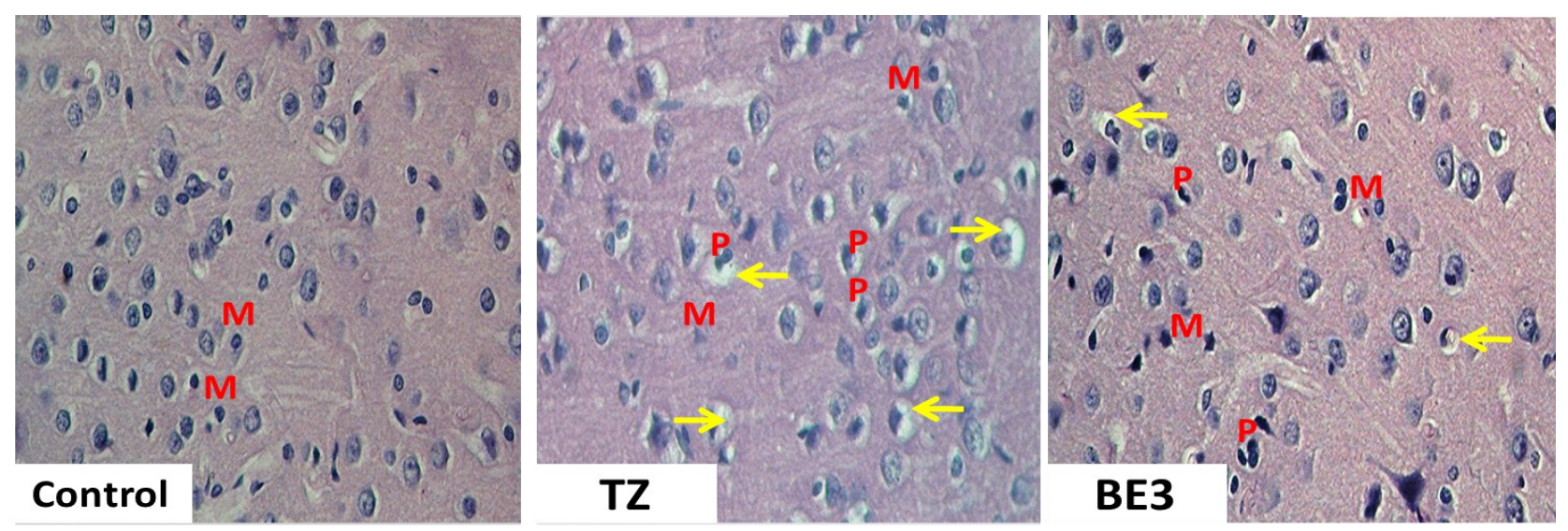

Fig. 4. Effect of broccoli extract on Cerebral cortex of brain against TZ induced toxicity (Magnification: 400x, Stain: Eosin and hematoxylin) Arrows showing neuron swelling and vacuolation; P: Pyknotic degenerating neurons; M: microglial neurons.

against the Nigella sativa oil supplementation having antioxidative properties (Rezvanfar et al., 2010). Decreased SOD levels in the brain undoubtedly resulted in the number of ROSs. More SOD is required to capture free radicals and $B E$ administration lead to overexpression of SOD, GPx, and CAT their elevated levels helped in detoxification of intermediate metabolites of TZ and ROSs from the body.

Enzymatic antioxidants such as SOD, GPx, and CAT levels are increased in the tissues due to the antioxidative property of broccoli which helped to initiate the adaptive response to the increased oxidative stress caused by TZ. LPO is a good indicator to assess the magnitude of the oxidative damage produced by ROS in the brain. Increased brain LPO may be linked to higher production of free radicals as seen after $T Z$ treatment, suggesting that the brain may be more prone to TZ-induced oxidative damage and increased LPO in TZ treated rats confirm a relationship between the degrees of toxicity in the brain to the altered endogenous antioxidants. Similar observations with chlorpyrifos treatment have also been observed in the brain of 

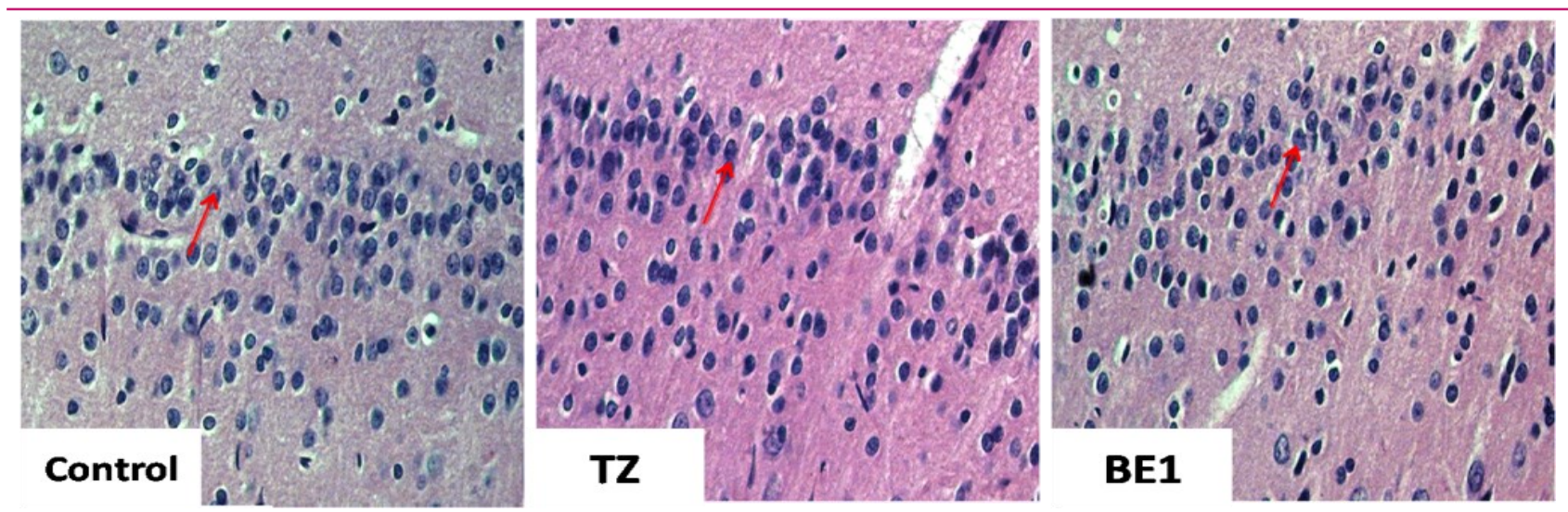

Fig. 5. Effect of broccoli extract on monomorphic pattern of neurons within the pyramidal layer of hippocampus region of brain (Magnification: 400x, Stain: Eosin and hematoxylin) Arrows showing monomorphic pattern of neurons within the pyramidal layer of hippocampus.
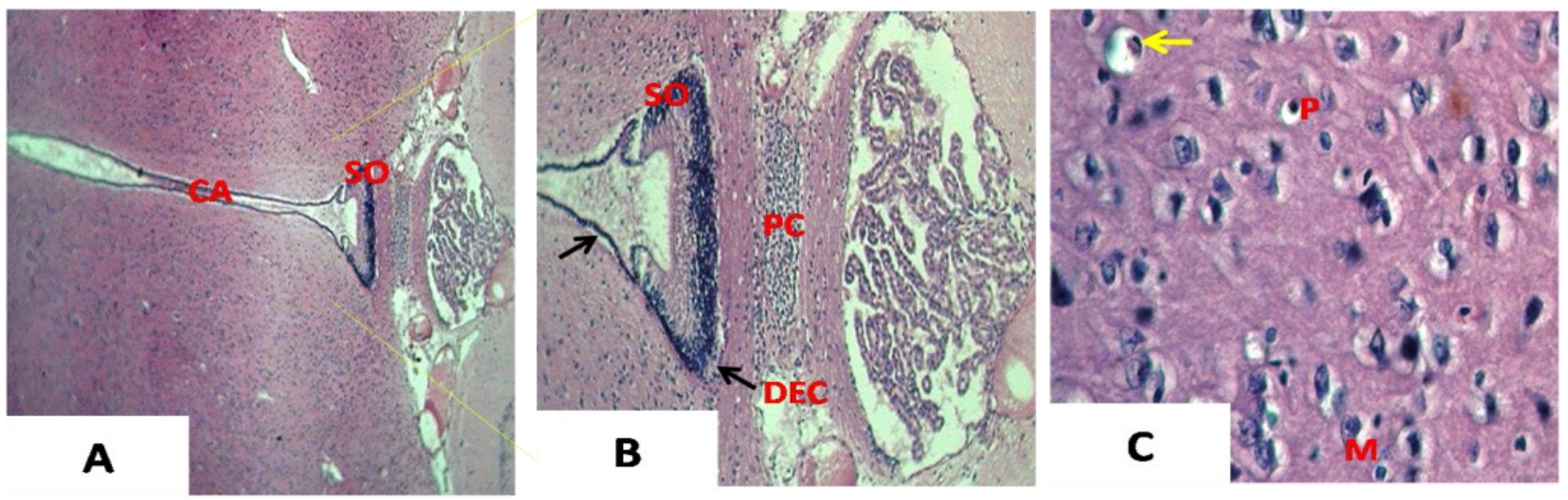

Fig. 6. A. and B. Effect of $T Z$ on subcommissural organ (SO) and C. cerebral cortex of brain histoarchitecture (Magnification: 100x, 200x and 400x; Stain: Eosin and hematoxylin) Black Arrows showing distorted ependymal cells (DEC); Yellow Arrow showing neuron swelling and vacuolation; CA: cerebral aqueduct; PC: posterior commissure; P: Pyknotic neurons; M: microglial neurons.

rats and grape seed extract was found beneficial (Singh et al., 2013). Also, the addition of Nigella sativa oil against propoxur has led to a reduction in MDA levels in the rat brain (Mohamadin et al., 2010) further confirms our current findings.

Chronic exposure to monocrotophos has been shown to cause significant changes in brain and spleen, including affected granular cell neurons in the cerebrum region, distorted cerebral cortex with neuronal loss, and spleen of rats were observed with severe congestion and hypocellularity in white pulp follicles (Yaduvanshi et al., 2010). Spleen showed congestion, hypocellularity and mild to moderate distortions in germinal centers of white pulp follicles after TZ treatment, which were minimized and improved by BE treatment. Histopathological effects of maternal 4-tert octylphenol, an OP, exposure on spleen also showed distorted white pulp and increased destruction in the spleen regions (Barlas and Aydofan, 2009). Similarly, saffron (Crocus sativus) petal ethanolic extract, rich in natural antioxidants, has been found beneficial and supplementation improved the spleen histology in rats (Babaei et al., 2015) further consolidates present findings. Histological changes in brain tissues of TZ treated rats showed mild congestion and hemorrhage in internal regions of the cerebral cortex. These observations are in agreement with Yaduvanshi et al. (2010) findings monocrotophos, induced number of histological alterations in brain tissues of rats. TZ treatment induced neurons pyknosis, vacuolation and swelling, which were restored with $B E$ supplementation due to the neuroprotective activity of the BE and a significant recovery of neuronal damage, and decreased necrosis was observed. Circumventricular organs, such as subcommissural organ, lack the normal blood-brain barrier and are vulnerable to certain pharmaceutical and toxic compounds that normally cannot penetrate through an effective blood-brain barrier. Because of a lack of blood-brain barrier in these regions, their vulnerability makes their evaluation in toxicity studies particularly important (Yaduvanshi et al., 2010; Garman 2011). TZ induced damage in the subcommissural organ was ameliorated by BE supplementation. Further, isothiocyanates (glucosinolates) have a neuroprotective 
potential for the treatment of neurodegenerative diseases, as reported by Giacoppo et al., (2015) also supports present findings.

OPs increase free radicals production in the brain and lead to the activation of endogenous antioxidants of target cells, which is the most prominent defense mechanism against free radicals-induced damage (Rezvanfar et al., 2010). Further studies also showed that the protective effect of plant-derived natural antioxidants was associated with the amelioration of oxidative stress and the preservation of antioxidant enzymes balance induced by pesticides in the brain (Hussien et al., 2013). From the above discussion, it can be inferred that antioxidant enzymes clear free radicals, lowers lipid peroxidation by decreased release of MDA, and then reduces the degree of membrane damage. Reduced MDA levels, both in the brain and spleen, due to broccoli extract, has been attributed to a minimum loss of membrane lipids due to scavenging of free radicals by up-regulated endogenous antioxidants as well as by natural dietary antioxidants on their own. Thus cellular integrity has been restored and histoarchitecture of the brain and spleen was improved in all the $\mathrm{BE}+\mathrm{TZ}$ treated rats.

\section{Conclusion}

The present study showed that $\mathrm{TZ}$ induced oxidative damage and neuro-splenic toxicity in rats through altered stress biomarkers and histopathological conditions. Aqueous extract of broccoli sprouts had a strong antioxidant affinity to reverse the TZ toxic effects and helped in maintaining the structural integrity of the cell and histoarchitecture of both the brain and spleen. It is a preliminary study about the neuroprotective role of broccoli sprouts against OP pesticide; however, further studies are needed to explore the molecular mechanism underlying the role of extract components and their induced protection against pesticides associated neuro-splenic toxicity.

\section{ACKNOWLEDGEMENTS}

This research did not receive any specific grant from funding agencies in the public, commercial, or not-forprofit sectors. Authors are thankful to the Dean, College of Basic Sciences and Humanities, Punjab Agricultural University (PAU), Ludhiana and Head, Department of Zoology, PAU, Ludhiana (Punjab), India for providing financial assistance and infrastructure to carry out the research.

\section{Conflict of interest}

The authors declare that they have no conflict of interest.

\section{REFERENCES}

1. Adom, K, K. \& Liu, R.H. (2002). Antioxidant Activity of Grains. Journal of Agricultural and Food Chemistry, 50 (21), 6182-6187.

2. Aebi, H. (1983). Catalase methods in Enzymatic Analysis (ed) Bergmeryer HU Vol 3, Academic Press, New York. Pp. 276-86.

3. Agrawal. A. \& Sharma, B. (2010). Pesticides induced oxidative stress in mammalian systems: Review Article. International Journal Of Biological and Medical Research, 1(3), 90-104.

4. Ainsworth, E.A. \& Gillespie, K.M. (2007). Estimation of total phenolic content and other oxidation substrates in plant tissues using Folin-Ciocalteu reagent. Nature Protocols, 2(4), 875-7.

5. Babaei, A., Arshami, J., Haghparast, A. \& Mesgaran, M.D. (2014). Effects of saffron (Crocus sativus) petal ethanolic extract on hematology, antibody response, and spleen histology in rats. Avicenna Journal of Phytomedicine, 4(2), 103-109.

6. Baird, L. \& Dinkova-Kostova, A.T. (2011). The cytoprotective role of the Keap1-Nrf2 pathway. Archives of Toxicology, 85, 241-272.

7. Barlas, N. \& Aydofan, M. (2009). Histopathologic effects of maternal 4-tert-octylphenol exposure on liver, kidney and spleen of rats at adulthood. Archives of Toxicology, 83, 341-349.

8. Carlberg, I. \& Mannervik, B. (1985). Glutathione reductase. Methods Enzymology, 113, 484-490.

9. Cekic, C., Casella, C.R., Sag, D., Antignano, F., Kolb, J., Suttles, J., Hughes, M.R., Krystal, G. \& Mitchell, T.C. (2011). MyD88-dependent SHIP1 regulates proinflammatory signaling pathways in dendritic cells after monophosphoryl lipid A stimulation of TLR4. Journal of Immunology, 186, 3858-3865.

10. Chang, C.C., Yang, M.H., Wen, H.M. \& Chern, J.C. (2002). Estimation of Total Flavonoid Content in Propolis by Two Complementary Colorimetric Methods. Journal of Food and Drug Analysis, 10(3), 178-182.

11. Chaudiere, J. \& Ferrari-iliou, R. (1999). Intracellular antioxidants: from chemical to biochemical mechanisms. Food and Chemical Toxicology, 37, 949-962.

12. Chen, X.P., Chao, Y.S., Chen, W.Z. \& Dong, J.Y. (2017). Mother gestational exposure to organophosphorus pesticide induces neuron and glia loss in daughter adult brain. Journal of Environmental Science and Health, Part B, 52, 2. doi: $10.1080 / 03601234.2016 .1239973$

13. Chen, Y.J.D., Conte, J., Lin, Y., Gemelli, A., Castro, A., Yarlagadda, S., Gonzalez, S. \& Philips, N. (2008). Sulforaphane, an extract from broccoli, prevents skin cancer. Journal of Plastic Dermatology, 4, 165-166.

14. Gao, J., Naughton, S.X., Beck, W.D., Hernandez, C.M., Wu, G., Wei, Z., Yang, X., Bartlett, M.G. \& Terry, A.V.Jr. (2017). Chlorpyrifos and chlorpyrifos oxon impair the transport of membrane bound organelles in rat cortical axons. Neuro Toxicology, 62, 111-123.

15. Gao, Z., Xu, H., Chen, X. \& Chen, K. (2003). Antioxidant status and mineral contents in tissues of rutin and baicalin fed rats. Life Science. 73, 1599-607.

16. Garman, R.H. (2011). Histology of the Central Nervous System. Toxicologic Pathology, 39, 22-35. 
17. Gerhauser, C. (2013). Cancer chemoprevention and nutriepigenetics: state of the art and future challenges. Topics in Current Chemistry, 329, 73-132.

18. Ghosh, P.K. \& Philip, L. (2006). Environmental significance of atrazine in aqueous systems and its removal by biological processes: An overview. Global NEST Journal, 8(2), 159-78.

19. Giacoppo, S., Galuppo, M., lori, R., De Nicola, G.R., Bramanti, P. \& Mazzon, E. (2014). (RS)-glucoraphanin purified from Tuscan black kale and bioactivated with myrosinase enzyme protects against cerebral ischemia/ reperfusion injury in rats. Fitoterapia, 99, 166-77.

20. Giacoppo, S., Galuppo, M., Montaut, S., Iori, R., Rollin, P., Bramanti, P. \& Mazzon, E. (2015). An overview on neuroprotective effects of isothiocyanates for the treatment of neurodegenerative diseases. Fitoterapia, 106, 12-21.

21. Guerrero-Beltrán, C.E., Calderón-Oliver, M., PedrazaChaverri, J. \& Chirino, Y.I. (2012). Protective effect of sulforaphane against oxidative stress: recent advances. Experimental Toxicologic Pathology, 64, 503-508.

22. Habig, W.H., Pabst, M.J. \& Jakoby, W.B. (1974). Glutathione S-transferases. The first enzymatic step in mercapturic acid formation. The Journal of Biological Chemistry, 246, 7130-7139.

23. Hafeman, D.G., Sunde, R.A. \& Hoekstra, W.G. (1984). Effect of dietary selenium on erythrocyte and liver glutathione peroxidase in the rat. The Journal of Nutrition, 104, 580-587.

24. Hu, Q., Li, S., Qiao, E., Tang, Z., Jin, E., Jin, G. \& Gu, Y. (2014). Effects of boron on structure and antioxidative activities of spleen in rats. Biological Trace Element Research, 158(1), 73-80.

25. Hussien, H.M., Abdou, H.M. \& Yousef, M.I. (2013). Cypermethrin induced damage in genomic DNA and histopathological changes in brain and haematotoxicity in rats: The protective effect of sesame oil. Brain Research Bulletin, 92, 76-83.

26. Jeffery, E.H. \& Araya, M. (2009). Physiological effects of broccoli consumption. Phytochemistry Review, 8(1), 283-98.

27. Katiyar, C.K., Gupta, A., Kanjilal, S. \& Katiyar, S. (2012). Drug discovery from plant sources: An integrated approach. Ayu, 33(1), 10-9.

28. Khan, A.M., Raina, R., Dubey, N. \& Verma, P.K. (2017). Effect of deltamethrin and fluoride co-exposure on the brain antioxidant status and cholinesterase activity in Wistar rats. Drug and Chemical Toxicology doi: 10.1080/01480545.2017.1321009

29. Koh, E., Wimalasiri, K.M.S., Chassy, A.W. \& Mitchell, A.E. (2009). Content of ascorbic acid, quercetin, kaempferol and total phenolics in commercial broccoli. Journal of Food Composition and Analysis, 22, 637-643.

30. Leibson, T. \& Lifshutz, M. (2008). Organophosphate and carbamate poisoning: review of the current literature and summary of clinical and laboratory experience in Southern Israel. The Israel Medical Association Journal, 10, 767- 770.

31. Li, W., Qiu, S. \& Wu, Y. (2008). Triazophos residues and dissipation rates in wheat crops and soil. Ecotoxicology and Environmental Safety, 69(2), 312-16.

32. Lowry, O.H., Rosebrough, N.J., Farr, A.L. \& Randall, A.J. (1951). Protein measurement with folin phenol reagent. Journal of Biological Chemistry, 193, 265-75.

33. Mansour, S.A. \& Mossa, A.H. (2010). Oxidative damage, biochemical and histopathological alterations in rats exposed to chlorpyrifos and the antioxidant role of zinc. Pesticide Biochemistry and Physiology, 96, 14-23.

34. Marklund, S. \& Marklund, G. (1974). Involvement of the superoxide anion radical in the autoxidation of pyrogallol and a convenient assay for superoxide dismutase. European Journal of Biochemistry, 47, 469-474.

35. Mohamadin, A.M., Sheikh, B., Abd El-Aal, A.A., Elberry, A.A. \& Al-Abbasi, F.A. (2010). Protective effects of Nigella sativa oil on propoxur-induced toxicity and oxidative stress in rat brain regions. Pesticide Biochemistry and Physiology, 98, 128-134.

36. Moller, P., Ploger, A. \& Sørensen, H. (1985). Quantitative analysis of total glucosinolate content in concentrated extracts from double low rapeseed by the Pdglucosinolate complex method. In: Sørensen $\mathrm{H}_{\text {., }}$ editor. (ed.) Advances in the Production and Utilization of Cruciferous Crop, Martinus Nijhoff/DR W. Junk Publishers, Dordrecht, pp. 97-110.

37. Pajovic, S.B., Saicic, Z.S., Spasic, M.B. \& Petrovic, M.B. (2003). The effect of ovarian hormones on antioxidant enzyme activities in the brain of male rats. Physiological Reviews, 52, 189-194.

38. Paśko, P., Krośniak, M., Prochownik, E., TyszkaCzochara, M., Fołta, M., Francik, R., Sikora, J., Malinowski, M. \& Zagrodzki, P. (2018). Effect of broccoli sprouts on thyroid function, haematological, biochemical, and immunological parameters in rats with thyroid imbalance. Biomedicine \& Pharmacotherapy, 97, 82-90.

39. Ren, J., Fan, C., Chen, N., Huang, J. \& Yang, Q. (2011). Resveratrol pretreatment attenuates cerebral ischemic injury by upregulating expression of transcription factor Nrf2 and HO-1 in rats. Neurochemical Research, 36, 2352 -2362 .

40. Rezvanfar, M.A., Rezvanfar, M.A., Ranjbar, A., Baeeri, M., Mohammadirad, A. \& Abdollahi, M. (2010). Biochemical evidence on positive effects of rolipram a phosphodiesterase-4inhibitor in malathion-induced toxic stress in rat blood and brain mitochondria. Pesticide Biochemistry and Physiology, 98, 135-143.

41. Sajeesh, T., Arunachalam, K. \& Parimelazhagan, T. (2011). Antioxidant and antipyretic studies on Pothos scandens L. Asian Pacific Journal of Tropical Medicine, 4, 889-99.

42. Saoudi, M., Hmida, I.B., Kammoun, W., Rebah, F.B., Jamoussi, K. \& Feki, A.E. (2017). Protective effects of oil of Sardinella pilchardis against subacute chlorpyrifosinduced oxidative stress in female rats. Archives of Environmental Occupational Health, doi: 10.1080/19338 244.2017.1317627

43. Sharma, D. \& Sangha, G.K. (2014). Triazophos induced oxidative stress and histomorphological changes in liver and kidney of female albino rats. Pesticide Biochemistry and Physiology, 110, 71-80.

44. Sharma, D. \& Sangha, G.K. (2018). Antioxidative effects of aqueous extract of broccoli sprouts against Triazophos induced hepatic and renal toxicity in female Wistar rats. Journal of Applied Biomedicine, 16(2), 100-110.

45. Sharma, D., Sangha, G.K. \& Khera, K.S. (2015). Triazophos induced oxidative stress and histomorphological changes in ovary of female Wistar rats. Pesticide Biochemistry and Physiology, 117, 9-18. 
46. Sharma, D., Sangha, G.K. \& Khera, K.S. (2015a). Effect of Preconceptional Exposure of Triazophos Formulation on Fertility and Reproductive Performance of Female Wistar Rats, Rattus norvegicus. Proceedings of the National Academy of Sciences, India Section B: Biological Sciences, 85(4), 987-992.

47. Sharma, P. \& Singh, R. (2012). Efficacy of trans-2hydroxycinnamic acid against trichlorfon-induced oxidative stress in Wistar rats. Toxicology International, 19(3), 295-300.

48. Singh, S., Kaur, S. \& Budhiraja, R.D. (2013). Chlorpyrifosinduced oxidative stress in rat's brain and protective effect of grape seed extract. Journal of Phytopharmacology, 2(3), 26-33.

49. Smida, A., Ncibi, S., Taleb, J., Saad, A.B., Ncib, S. \& Zourgui, L. (2017). Immunoprotective activity and antioxidant properties of cactus (Opuntia ficus indica) extract against chlorpyrifos toxicity in rats. Biomedicine Pharmacotherapy, 88, 844-851.

50. Stocks, J. \& Dormandy, T.L. (1971). The autoxidation of human red cell lipids induced by hydrogen peroxide. British Journal of Haematology, 120(1), 95-111.

51. Uzun, F.G. \& Kalender, Y. (2011). Protective effect of vitamin $C$ and $E$ on malathion induced nephrotoxicity in male rats. Gazi University Journal of Science, 24(2), 193-200.

52. Voss G, Sachsse K (1970). Red cell and plasma cholinesterase activities in microsamples of human and animal blood determined simultaneously by a modified acetylthiocholine/DTNB procedure. Toxicology and Applied Pharmacology, 16, 764-777.
53. Vouldoukis, I., Lacan, D., Kamate, C., Coste, P., Calenda, A., Mazier, D., Conti, M. \& Dugas, B. (2004). Antioxidant and anti-inflammatory properties of a Cucumis melo LC. Extract rich in superoxide dismutase activity. Journal of Ethnopharmacology, 94, 67-75.

54. Wang, P., Wang, J., Sun, Y.J., Yang, L. \& Wu, Y.J. (2017). Cadmium and chlorpyrifos inhibit cellular immune response in spleen of rats. Environmental Toxicology, 32, 1927-1936.

55. Wu, J., Li, Z., Wu, L., Zhong, F., Cui, N., Dai, Y. \& Cheng, S. (2017). Triazophos (TAP) removal in horizontal subsurface flow constructed wetlands (HSCWs) and its accumulation in plants and substrates. Scientific Reports, 7, 5468 doi:10.1038/s41598-017-05874-0

56. Wu, J.C., Lai, C.S., Tsai, M.L. \& Pan, M.H. (2017a). Chemopreventive effect of natural dietary compounds on xenobiotic-induced toxicity. Journal of Food and Drug Analysis, 25, 176-186.

57. Yaduvanshi, S.K., Oiha, A., Pant, S.C., Lomash, V. \& Srivastava, N. (2010). Monocrotophos induced lipid peroxidation and oxidative DNA damage in rat tissues. Pesticide Biochemistry and Physiology, 97, 214-222.

58. Zhan, H., Huang, F., Yan, F., Zhao, Z., Zhang, J., Cui, T., Yang, F., Hai, G., Jia, X. \& Shi, Y. (2017). Alterations in splenic function and gene expression in mice with depressive-like behavior induced by exposure to corticosterone. International Journal of Molecular Medicine, 39(2), 327-336. 